\title{
STUDI HUBUNGAN ARUS LALU LINTAS \\ DI RUAS JALAN RUNGKUT ASRI KOTA MADYA SURABAYA DENGAN METODE UNDERWOOD
}

\author{
Hendrata Wibisana \\ Dosen Jurusan Teknik Sipil FTSP, \\ Universitas Pembangunan Nasional "Veteran”, Jawa Timur. \\ E-mail: hw00198@yahoo.com
}

\begin{abstract}
ABSTRAK
Karakteristik dari arus lalu lintas dapat dipelajari dan dianalisis dengan menggunakan beberapa metode. Pada penelitian ini salah satu metode yang digunakan adalah Metode Underwood yang menyatakan bahwa hubungan matematis dari arus dan kerapatan merupakan fungsi logaritmik. Dari hasil pengolahan data arus lalu lintas pada ruas jalan Rungkut Asri di kotamadya Surabaya, berdasarkan metode Underwood dan pengolahan grafik dengan Regresi linier diperoleh nilai Sff (kecepatan pada kerapatan terendah) diperoleh sebesar 85,357 km/jam dan nilai Dj (kerapatan tertinggi) diperoleh sebesar 66,67 ( $\mathrm{smp} / \mathrm{km})$. Volume maksimum diperoleh pada kondisi kepadatan D $=33,335 \mathrm{smp} / \mathrm{km}$ yang bergerak dengan kecepatan $\mathrm{S}=43,678 \mathrm{~km} / \mathrm{jam}$. Model matematis diperoleh sebagai berikut: Ln.S = 4,47 - 0,015 D; V = 87,357 D.e $\mathrm{e}^{(-0,015 \mathrm{D})} ; \mathrm{V}=447 \mathrm{~S}-66,67 \mathrm{Sln} . \mathrm{S}$
\end{abstract}

Kata Kunci: Metode Underwood, Speed vehicles, Traffic flow, Density of traffic.

\begin{abstract}
Characteristic from the traffic flow could be learn and analysis using several methods. In this research one of the methods is Underwood Methods, where the method is says that there is mathematical correlation between the volume and density of traffic. And the correlation according Underwood is a logarithmic function. From the calculation of the traffic flow at the Rungkut Asri road in Surabaya city. Base on the Underwood and the graphic manipulation with linier regression has the result where is point of Sff is a 85,357 km/hr and Dj has a volume 66,67 vpu/km. Maximum volume could be reach in condition volume the density of traffic $\mathrm{D}=33,335 \mathrm{vpu} / \mathrm{km}$ that moving with velocity $\mathrm{S}=43,678$ $\mathrm{km} / \mathrm{hr}$. Mathematical models can be presented with this equation like: Ln.S = 4,47 - 0,015.D and $\mathrm{V}=$ 87,357.D. $\mathrm{e}^{(-0,015 \mathrm{D})}$ and $\mathrm{V}=447 . \mathrm{S}-66,67 . S . \ln S$.
\end{abstract}

Keywords: Underwood Methods, Speed vehicles, Traffic flow, Density of traffic.

\section{PENDAHULUAN}

Pembangunan ruas jalan sebagai salah satu bentuk komitmen pemerintah dalam pembangunan infrastruktur secara menyeluruh dimaksudkan sebagai penyedia sarana transportasi yang memudahkan masyarakat setempat untuk berinteraksi dengan lingkungan sekitarnya, baik dalam bidang sosial, ekonomi maupun budaya. Sebagai salah satu sarana transportasi darat ,jalan raya dimaksudkan untuk dipergunakan sebagai akumulasi berbagai kendaraan bermotor maupun kendaraan tak bermotor. Dan dalam hal ini jumlah atau volume dari kendaraan yang melintasi jalan tersebut tergantung kepada parameter yang ada yang menimbulkan "bangkitan pergerakan”. Menurut Tamin (Tamin, 2003), tujuan dasar 
bangkitan pergerakan adalah menghasilkan model hubungan yang mengkaitkan parameter tata guna lahan dengan jumlah pergerakan yang menuju ke suatu zona atau jumlah pergerakan yang meninggalkan suatu zona. Jumlah pergerakan dapat dikaitkan dengan kerapatan arus lalu lintas pada suatu ruas jalan. Kerapatan dapat diyakini berkorelasi dengan kecepatan kendaraan serta volume kendaraan yang terjadi per kilometer ruas jalan.

Penelitian ini dimaksudkan untuk mencari model korelasi antara volume kendaraan, arus dan kecepatan kendaraan pada suatu ruas jalan. Ruas jalan yang diteliti pada area Rungkut Asri. Pemilihan ini didasari oleh observasi awal dimana pada ruas jalan ini sering terjadi kemacetan, volume kendaraan yang meningkat pada jam-jam tertentu, serta belum ada suatu studi yang memodelkan korelasi arus dan kepadatan pada ruas jalan ini.

Tujuan dari penelitian ini antara lain:

1. Menghitung berapa Nilai Sff dan kepadatan maksimum (Dmaks).

2. Mencari model matematis antara Kecepatan-Kepadatan, Volume-Kecepatan dan Volume-Kepadatan

3. Menentukan berapa kapasitas (volume maksimum) dan pada kondisi yang bagaimana Volume maksimum terjadi pada ruas jalan tersebut

\section{TINJAUAN PUSTAKA}

Karakteristik arus lalu lintas pada suatu area menarik untuk diteliti dan dianalisis, dimana hasil yang diperoleh dapat merepresentasikan kondisi dari ruas jalan yang ada. Dalam hal ini dikenal ada 3 parameter yang utama yaitu:

1. Arus (volume) lalu lintas

2. Kerapatan (densitas) lalu lintas

3. Kecepatan (speed) lalu lintas

Menurut Tamin karakteristik ini dapat dipelajari dengan suatu hubungan matematik di antara ketiga parameter di atas yaitu kecepatan, arus dan kerapatan lalu lintas pada ruas jalan.

Hubungan matematis tersebut dapat dinyatakan dalam Persamaan 1.

$\mathrm{V}=\mathrm{D} . \mathrm{S}$

$$
\text { dimana: } \begin{aligned}
\mathrm{V} & =\text { arus } \\
\mathrm{D} & =\text { kepadatan } \\
\mathrm{S} & =\text { kecepatan }
\end{aligned}
$$

Hubungan di atas bila dijelaskan dalam Gambar 1, Gambar 2, dan Gambar 3. 


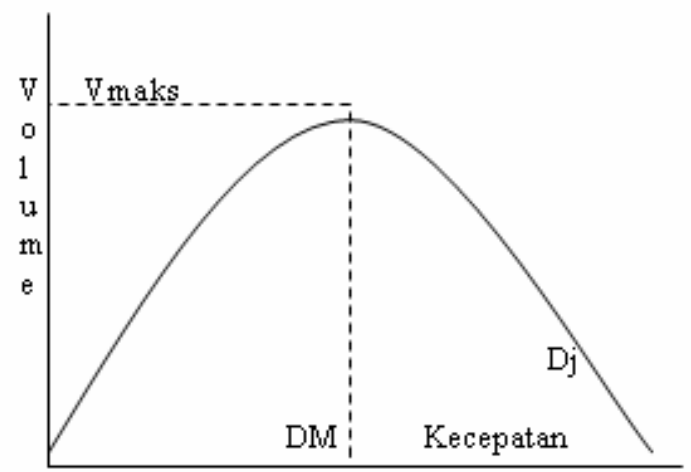

Gambar 1. Kecepatan Vs Volume

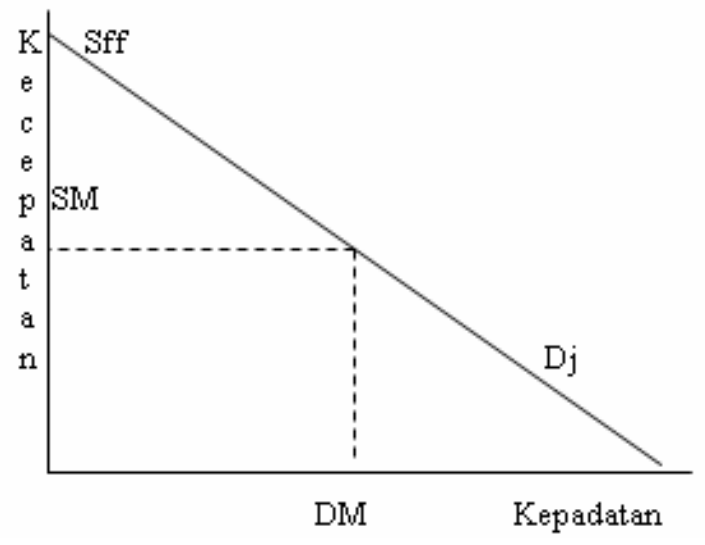

Gambar 2. Kerapatan Vs Kecepatan

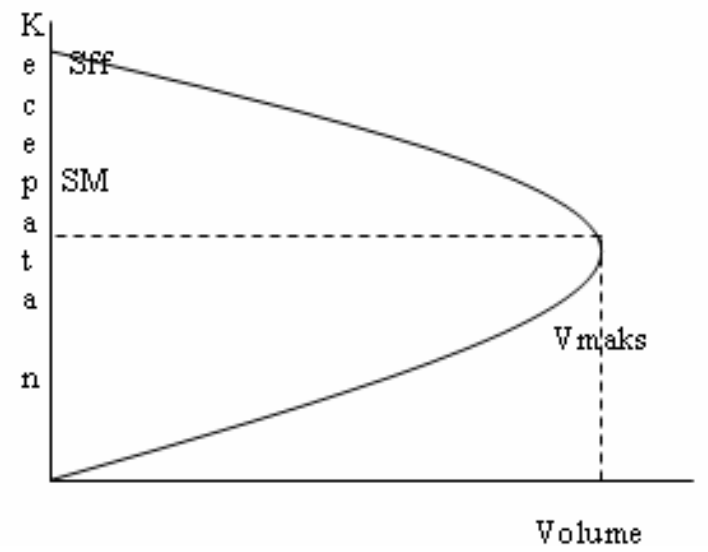

Gambar 3. Volume vs Kecepatan

Keterangan Gambar 1, Gambar 2, dan Gambar 3 sebagai berikut:

$$
\begin{array}{ll}
\mathrm{VM} & =\text { kapasitas atau arus maksimum (kendaraan } / \mathrm{jam}) \\
\mathrm{SM} & =\text { kecepatan pada kondisi arus lalu lintas maksimum }(\mathrm{km} / \mathrm{jam}) \\
\mathrm{DM} & =\text { kerapatan pada kondisi arus lalu lintas maksimum }(\text { kendaraan/ km) } \\
\mathrm{Dj} & =\text { kerapatan pada kondisi arus lalu lintas macet total }(\text { kendaraan/ km })
\end{array}
$$


Penurunan Model yang dapat menyatakan atau merepresentasikan hubungan antara Kerapatan dan Kecepatan ada 3 yaitu:

1. Model Greenshield

2. Model Greenberg

3. Model Underwood

Pada penelitian ini hanya akan dibahas model yang ketiga yaitu model Underwood dan rute yang diambil sebagai sample adalah ruas jalan utama Rungkut Asri Kodya Surabaya dengan jumlah pengukuran sebanyak 22.

\subsection{Model Underwood}

Underwood mengasumsikan bahwa hubungan matematis antara kecepatan dan kepadatan bukan merupakan fungsi linier melainkan fungsi "logaritmik".

Persamaan dasar model underwood dapat dinyatakan melalui persamaan :

$$
S=\operatorname{Sff} . e^{D / D m}
$$

dimana : Sff = kecepatan arus bebas

Dm = kerapatan pada kondisi arus maksimum (kapasitas ).

Jika Persamaan 2 di atas dinyatakan dalam bentuk logaritma natural, maka Persamaan 2 dapat dinyatakan kembali sebagai Persamaan 3 dan Persamaan 4, sehingga hubungan matematis antara Kecepatan-Kerapatan selanjutnya juga dapat dinyatakan dalam Persamaan 4.

$$
\begin{aligned}
& \text { Ln. S = ln. Sff . + ln. e } \\
& \text { Ln. S = Ln. Sff }-\quad-\frac{D}{----}
\end{aligned}
$$

Selanjutnya hubungan matematis antara Arus-Kecepatan dapat diturunkan dengan menggunakan Persamaan 1, dan dengan memasukkan Persamaan 5.

$$
S=\frac{\text { V }}{----}
$$


Persamaan apabila dimasukkan ke persamaan (2), diperoleh dan diturunkan persamaan selanjutnya dalam bentuk persamaan (6) dan persamaan ( 7) :

$$
\begin{aligned}
& \text { V }---=\text { Sff } . e^{\mathrm{D} / \mathrm{Dm}} \\
& \mathrm{D} \\
& \mathrm{V}=\text { D. Sff } . \mathrm{e}^{\mathrm{D} / \mathrm{Dm}}
\end{aligned}
$$

Persamaan ( 7) adalah persamaan yang menyatakan huungan matematis antara ArusKerapatan. Kondisi arus maksimum ( Vm) bisa diperoleh pada saat arus D $=$ Dm. Nilai D $=$ Dm bisa diperoleh dari persamaan:

$$
\begin{aligned}
& \begin{array}{cc}
\mathrm{V} \\
---- \\
\mathrm{D}
\end{array}=\mathrm{Sff}-\stackrel{2 . \mathrm{Sff}}{------.} \mathrm{Dm}=0 \\
& \mathrm{Dm}=\frac{\mathrm{Dj}}{-----}
\end{aligned}
$$

dengan memasukkan persamaan (9) ke persamaan (7), maka nilai Vm bias didapat dan diperoleh persamaan baru sebagai berikut:

$$
\mathrm{VM}=\frac{\mathrm{Dj} \text {. Sff }}{----}
$$

\section{METODA PENELITIAN}

\subsection{Pengambilan Data}

1. Survey dan pengambilan data dilakukan pada ruas jalan Rungkut Asri.

2. Pengambilan data dilakukan mulai jam 06.00 WIB hingga selesai jam 17.00 WIB dengan cara menghitung jumlah kendaraan bermotor yang melintasi ruas jalan tersebut dan di total tiap 30 menit berjalan.

3. Untuk data kecepatan (S), pengambilan data dilakukan dengan terlebih dahulu mengukur panjang ruas jalan percobaan dan setelah itu dengan bantuan stopwatch mengukur waktu lintasan kendaraan bermotor dari titik awal ke titik akhir.

\subsection{Tabulasi Data}

Data yang selesai dibuat, ditabulasikan dengan bantuan program komputer Excel 2000 dan dilakukan perhitungan untuk D dan Xi kuadrat dan dimasukkan dalam kolom tersendiri pada Excel. 


\subsection{Analisis Data}

Untuk analisis data dilakukan dengan menggunakan Regresi Linier:

$\mathrm{Yi}=\mathrm{A}+\mathrm{Bxi}$

Dengan transformasi linier diperoleh:

Ln. $\mathrm{S}=\mathrm{Yi}$

$\mathrm{D}=\mathrm{Xi}$

A adalah perpotongan dengan sumbu $\mathrm{Y}$, maka diperoleh $\mathrm{A}=\mathrm{Ln}$. Sff, sedangkan B adalah gradien atau kemiringan dari kurva sehingga diperoleh,

$$
\begin{aligned}
& B=-1 / D m \\
& \text { Sff }=e^{A} .
\end{aligned}
$$

Untuk mencari nilai A dan B diberikan rumusan di bawah ini yang diturunkan dari metode kuadrat terkecil atau dari analisis regresi biasa:

$$
\begin{aligned}
& B=\frac{N \sum_{i=1}^{N}\left(X_{i} Y_{i}\right)-\sum_{i=1}^{N} X_{i} \cdot \sum_{i=1}^{N} Y_{i}}{N \sum_{i=1}^{N}\left(X_{i}\right)^{2}-\left(\sum_{i=1}^{N} X_{i}^{2}\right)} \\
& A=\frac{\sum_{i=1}^{N} Y_{i}}{N}-B \cdot \frac{\sum_{i=1}^{N} X_{i}}{N}
\end{aligned}
$$

Karena Sff $=$ A , maka $\mathrm{Dj}=-(\mathrm{A} / \mathrm{B})$

\section{HASIL DAN ANALISIS}

Data yang diperoleh dari hasil pengukuran di lapangan dinyatakan pada Tabel 1 . Untuk keperluan analisis regresi dibuat tambahan kolom guna perhitungan nilai D dan Xi kuadrat. Hasil tersebut ditampilkan pada Tabel.2 
Tabel.1. Data Pengukuran Arus Lalu Lintas dan Kecepatan

\begin{tabular}{|c|c|c|c|}
\hline NO & PERIODE & $\bar{v}$ & $S$ \\
\hline & & $(\mathrm{smo} / \mathrm{jom})$ & $\mathrm{km} / \mathrm{jom}$ ) \\
\hline 1 & 2 & 3 & 4 \\
\hline 1 & $06.00-0630$ & 98525 & 7251 \\
\hline 2 & $0630-07.00$ & 15652 & 64.35 \\
\hline 3 & $07.00-07.300$ & 15475 & 60.25 \\
\hline 4 & 07.3008 .00 & 1425.32 & 64.35 \\
\hline 5 & $08.00-0830$ & 125644 & 61.42 \\
\hline 6 & 083009.00 & 1026.35 & 6524 \\
\hline 7 & $09.00-09.30$ & 1124.15 & 7215 \\
\hline 8 & $0930-10.00$ & 989.56 & 78.15 \\
\hline 9 & $10.00-10.30$ & 104525 & 7242 \\
\hline 10 & $10.30-11.00$ & 987.56 & 67.66 \\
\hline 11 & $11.00-11.30$ & 85421 & 75.65 \\
\hline 12 & $11.30-1200$ & 899.54 & 7234 \\
\hline 13 & $1200-1230$ & 113125 & 67.35 \\
\hline 14 & $1230-13.00$ & 125124 & 58.55 \\
\hline 15 & $13.00-13.30$ & 104235 & 66.57 \\
\hline 16 & $13.30-14.00$ & 951.45 & 70.06 \\
\hline 17 & $14.00-14.30$ & 86524 & 7221 \\
\hline 18 & $14.300-1500$ & 925.15 & 71.06 \\
\hline 19 & $15.00-1530$ & 825.65 & 71.35 \\
\hline 20 & $15.30-16.00$ & 946.65 & 74.45 \\
\hline 21 & $16.00-16.30$ & 1045.54 & 7025 \\
\hline $\mathbf{2 2}$ & $16.30-17.00$ & 125525 & 64.85 \\
\hline
\end{tabular}

Tabel.2. Data Penghitungan Nilai Kerapatan dan Kecepatan

\begin{tabular}{|c|c|c|c|c|c|c|}
\hline No & $\begin{array}{c}\mathrm{V} \\
(\mathrm{smp} / \mathrm{jam})\end{array}$ & $\begin{array}{c}\mathrm{S} \\
(\mathrm{km} / \mathrm{jam})\end{array}$ & $\mathrm{d}=\mathrm{v} / \mathrm{s}=\mathrm{Xi}$ & $\log \mathrm{S}=\mathrm{Yi}$ & $\mathrm{Xi}^{*} \mathrm{Yi}$ & $\left(\mathrm{Xi}^{\wedge} \mathbf{2}\right)$ \\
\hline 1 & 2 & 3 & 4 & 5 & 6 & 7 \\
\hline 1 & 985.25 & 72.51 & 13.587781 & 4.283724483 & 58.20631013 & 184.6277924 \\
\hline 2 & 1565.2 & 64.35 & 24.32323232 & 4.164336934 & 101.2901347 & 591.6196306 \\
\hline 3 & 1584.75 & 60.25 & 26.30290456 & 4.098502572 & 107.802522 & 691.8427885 \\
\hline 4 & 1425.32 & 64.35 & 22.14949495 & 4.164336934 & 92.23795989 & 490.6001265 \\
\hline 5 & 1256.44 & 61.42 & 20.45652882 & 4.117735515 & 84.23457523 & 418.4695713 \\
\hline 6 & 1026.35 & 65.24 & 15.73191294 & 4.178072778 & 65.72907718 & 247.4930847 \\
\hline 7 & 1124.15 & 72.15 & 15.58073458 & 4.278747285 & 66.66602579 & 242.7592901 \\
\hline 8 & 989.56 & 78.15 & 12.66231606 & 4.358630057 & 55.19035136 & 160.334248 \\
\hline 9 & 1045.25 & 72.42 & 14.43316763 & 4.282482504 & 61.80978787 & 208.3163279 \\
\hline 10 & 987.56 & 67.66 & 14.59592078 & 4.214495163 & 61.51443753 & 213.0409034 \\
\hline 11 & 854.21 & 75.65 & 11.29160608 & 4.32611744 & 48.84881399 & 127.5003679 \\
\hline 12 & 889.54 & 72.34 & 12.29665469 & 4.281377227 & 52.64661734 & 151.2077165 \\
\hline 13 & 1131.25 & 67.35 & 16.796585 & 4.209902903 & 70.71199197 & 282.1252678 \\
\hline 14 & 1251.24 & 58.55 & 21.3704526 & 4.06988109 & 86.97520094 & 456.6962445 \\
\hline 15 & 1042.35 & 66.57 & 15.65795403 & 4.198254026 & 65.73606855 & 245.1715245 \\
\hline 16 & 951.45 & 70.06 & 13.58050243 & 4.249352018 & 57.70833539 & 184.4300462 \\
\hline 17 & 865.24 & 72.21 & $11.9 \$ 227392$ & 4.27957854 & 51.27908235 & 143.5748884 \\
\hline 18 & 925.15 & 71.06 & 13.01927948 & 4.263524591 & 55.50801822 & 169.5016382 \\
\hline 19 & 825.65 & 71.35 & 11.57182901 & 4.267597344 & 49.38390676 & 133.9072267 \\
\hline 20 & 946.65 & 74.45 & 12.71524513 & 4.310127759 & 54.804331 & 161.6774587 \\
\hline 21 & 1045.54 & 70.25 & 14.88313167 & 4.252060308 & 63.28397345 & 221.5076084 \\
\hline 22 & 1255.25 & 64.85 & 19.35620663 & 4.172076911 & 80.75558276 & 374.6627351 \\
\hline SUM & 23973.35 & 1513.19 & 354.3457143 & 93.02091438 & 1492.323104 & 6101.066486 \\
\hline
\end{tabular}


Dari Tabel 2 nilai A dan B dapat dihitung dengan memakai persamaan 14, setelah lebih dahulu masing-masing kolom dalam table tersebut ditotal masing-masing kolom yang ada.

$$
\begin{aligned}
& \text { (22).(1492,323)-(354,345)(93,021) } \\
& \text { B = ---.-(22).(6101,066)- }(354,345)^{2} \\
& 32831,106-32961,526 \\
& \text { B = - ---------------------- } \\
& \mathrm{B}=-0,015 \\
& A=4,228-(-0,0015) * 16,107 \\
& A=4,228+0,242 \\
& A=4,47 \\
& \text { Sff }=\text { e. }^{\text {A }} \\
& \text { Ln } . \text { Sff }=4,47 \\
& \text { Sff }=87,357 \mathrm{~km} / \mathrm{jam} \\
& 1 \\
& \mathrm{Dm}=- \\
& =66,67 \mathrm{smp} / \mathrm{km} \\
& (-0,0015)
\end{aligned}
$$

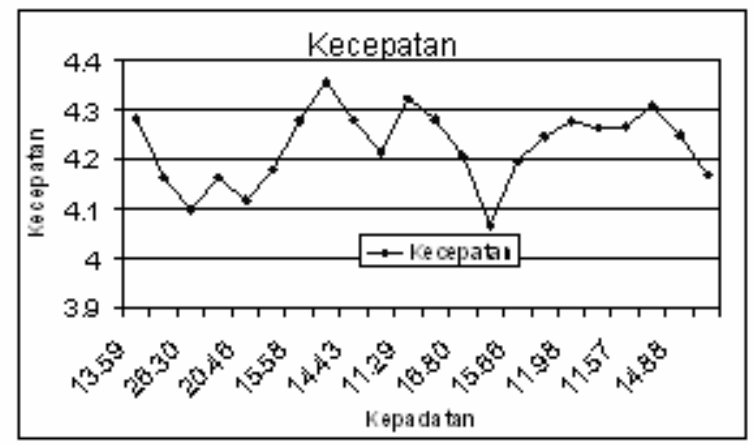

Gambar 4. Hubungan Kecepatan Dengan Kerapatan

Model matematis persamaan untuk Kecepatan-Kerapatan adalah:

$$
\text { Ln. } S=4,47-0,015 \mathrm{D}
$$

Model matematis persamaan untuk Volume- Kerapatan adalah:

$$
\mathrm{V}=87,357 \text { D. } \mathrm{E}^{-0,015 \mathrm{D}}
$$

Model matematis persamaan untuk Volume -Kecepatan adalah:

$$
\mathrm{V}=447 \mathrm{~S}-66,67 \mathrm{SLn} . \mathrm{S}
$$




\subsection{Penggambaran Kurva Model Matematis}

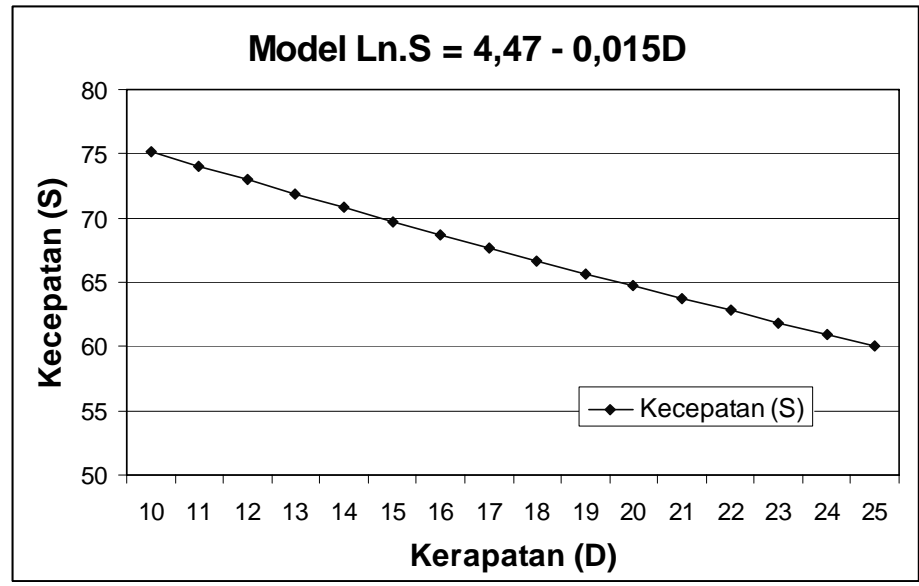

Gambar 5. Kurva Model Matematis 1

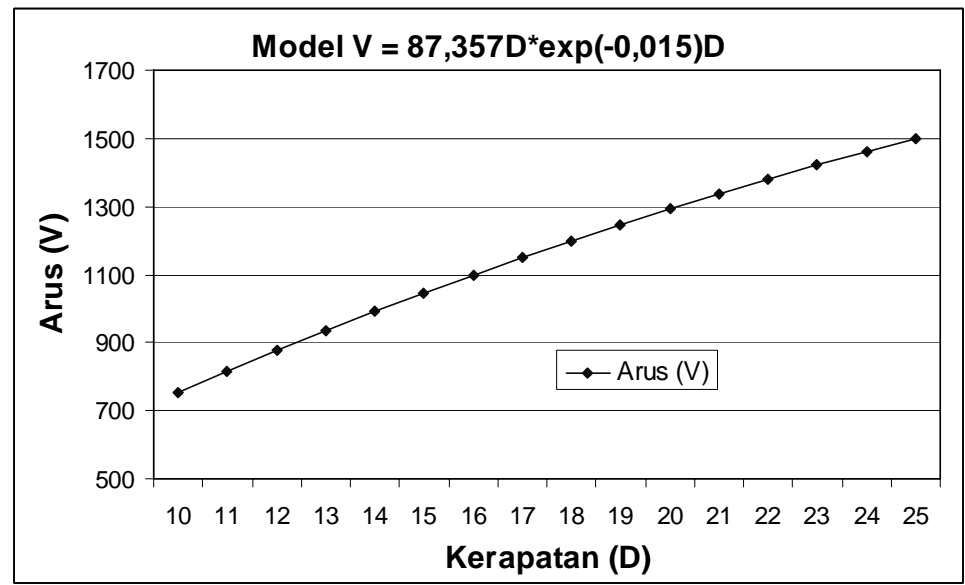

Gambar 6. Kurva Model Matematis 2

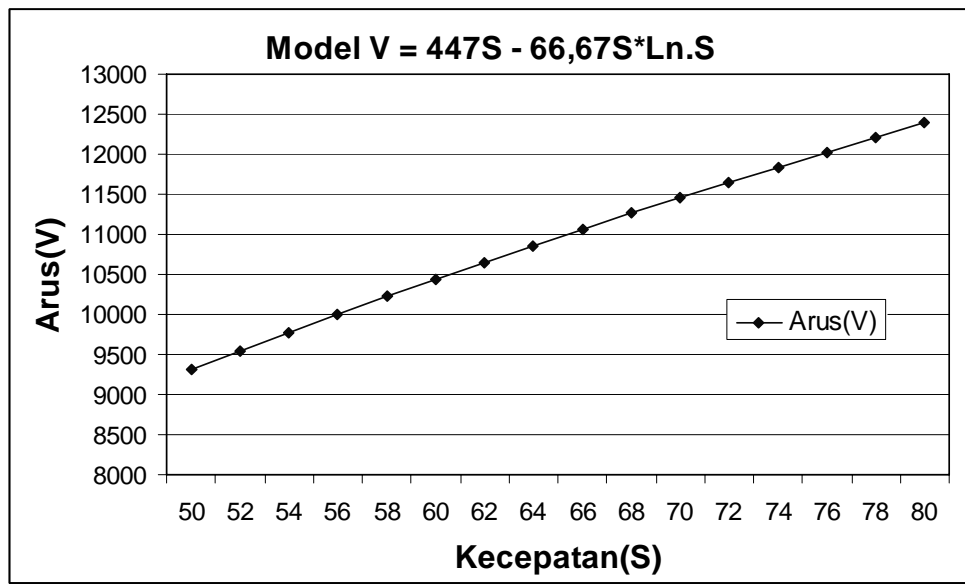

Gambar 7. Kurva Model Matematis 3 
Volume maksimum dapat dihitung dengan menggunakan Persamaan 12.

$$
\begin{aligned}
& \text { Dmaks = ----------- }=33,335(\mathrm{smp} / \mathrm{km}) \\
& \mathrm{S} \text { maks }=\frac{\text { 87,357 }}{--------}=\text { 43,678 km/jam }
\end{aligned}
$$

dengan memasukkan nilai Dmaks ke dalam Persamaan 13 diperoleh nilai Vmaks:

$$
\begin{aligned}
& \text { Vmaks }=87,357 \cdot(33,335) \cdot{ }^{*} \mathrm{e}^{(-0,015)(33,335)} \\
& \text { V maks }=2912,05 \cdot * \mathrm{e}(-0,5) \\
& \text { Log. Vmaks }=\log (2912,05)-0,5 \\
& \text { Log.Vmaks }=3,46-0,5=2,96 \\
& \text { Vmaks }=912 \mathrm{smp} / \mathrm{jam}
\end{aligned}
$$

\section{KESIMPULAN}

Kesimpulan dalam studi ini sebagai berikut:

1. Nilai Sff (kecepatan pada kepadatan terendah) diperoleh sebesar $87,357 \mathrm{~km} / \mathrm{jam}$.

2. Nilai Dj (kerapatan tertinggi) diperoleh sebesar 66,67 (smp/km).

3. Volume maksimum diperoleh pada kondisi kerapatan $\mathrm{D}=33,335 \mathrm{smp} / \mathrm{km}$ yang bergerak dengan kecepatan $S=43,678 \mathrm{~km} / \mathrm{jam}$.

4. Model matematis diperoleh :

$$
\begin{aligned}
& \text { Ln.S = 4,47 - 0,015 D } \\
& \text { V = 87,357 D. } \mathrm{e}^{(-0,015 \mathrm{D})} \\
& \mathrm{V}=447 \mathrm{~S}-66,67 \mathrm{Sln} . \mathrm{S}
\end{aligned}
$$

\section{PUSTAKA}

1. Tamin, O.Z., (2003). Perencanaan dan Pemodelan Transportasi”, Edisi Kesatu, ITB Bandung.

2. Khisty C.J., Kent Lall., (2003). Transportation Engineering An Introduction, Third Edition, Prentice Hall, New Jersey, 2003

3. Asian Development Bank, (2003). Panduan Keselamatan Jalan untuk Kawasan Asia Pasifik, Asian Development Bank, Manila.

4. Warpani S., (1990). Merencanakan Sistem Perangkutan, ITB, Bandung.

5. Bhattacharyya G.K.,Johnson R.A., (1977). Statistical Concepts and Methods, John Wiley \& Sons, New York. 